\title{
WHY ARE GASOLINE PRICES STICKY? A TEST OF ALTERNATIVE MODELS OF PRICE ADJUSTMENT
}

\author{
CHRISTOPHER DOUGLAS ${ }^{\mathrm{a}}$ AND ANA MARÍA HERRERA ${ }^{\mathrm{b} *}$ \\ ${ }^{a}$ Department of Economics, University of Michigan-Flint, Flint, MI, USA \\ ${ }^{\mathrm{b}}$ Department of Economics, Wayne State University, Detroit, MI, USA
}

\begin{abstract}
SUMMARY
Macroeconomic models of business cycles rely on the assumption that firms adjust prices infrequently to generate the short-run non-neutrality of money documented by the monetary transmission literature. They posit different mechanisms to generate price stickiness, with correspondingly different implications for inflation dynamics. Using an autoregressive conditional binomial model, we test which mechanism is most consistent with the pattern of price adjustment found in daily wholesale gasoline price data. Our results lead us to reject menu costs and information-processing delays but suggest that strategic considerations related to the idea of 'fair pricing' play an important role in accounting for price stickiness. Copyright (C) 2009 John Wiley \& Sons, Ltd.
\end{abstract}

Received 25 July 2008; Revised 22 January 2009

\section{INTRODUCTION}

Macroeconomic models of business cycles often make the assumption that firms adjust prices infrequently. ${ }^{1}$ The theoretical arguments for this assumption include (1) the existence of a menu cost firms must incur to change their price (Barro, 1972; Sheshinski and Weiss, 1977, 1983; Mankiw, 1985), (2) bounded rationality related to the costs of processing information (Mankiw and Reis, 2002; Sims, 2003; Reis, 2006a, 2006b), and (3) strategic interactions between a firm and its customers or competitors (Okun, 1981; Rotemberg, 1982, 2005, 2006).

Despite this rich theoretical background, the number of empirical studies on price rigidities was rather limited until the early 1990s (Levy, 2007). Yet, in recent years, the increasing popularity of the New Keynesian research program has bolstered a line of inquiry into various empirical features of price stickiness. This literature has provided interesting insights into the prevalence of

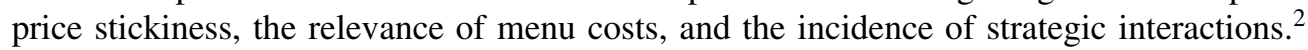

Our contribution to this literature is to investigate the implications of alternative theoretical models for the structure of time dependence. Specifically, does the probability of a price change reflect the history of price adjustments through channels other than the current price-cost gap? Is a firm more or less likely to change its price if it did so in the recent past? Given the widespread

\footnotetext{
* Correspondence to: Ana María Herrera, Department of Economics, Wayne State University, 656 W. Kirby, 2095 FAB, Detroit, MI 48 202, USA. E-mail: amherrera@wayne.edu

${ }^{1}$ Some examples are Rotemberg and Woodford (1997), Clarida et al. (1999), Chari et al. (2000), Erceg et al. (2003) and Dotsey and King (2006).

${ }^{2}$ For instance, Levy et al. (1997), Slade (1998), and Aguirregabiria (1999) find evidence in favor of the menu costs hypothesis; Slade (1999), Borenstein et al. (1997), Davis and Hamilton (2004), and Noel (2007a,b) find some indication that strategic interactions play an important role in explaining price stickiness.
}

Copyright @ 2009 John Wiley \& Sons, Ltd. 
use of time-dependent pricing models in macroeconomics, we believe studying the prevalence and form of time dependence in micro-level data on price changes can aid in choosing among alternative models of price stickiness.

Our aim is to explore whether the empirical implications of menu cost, information-processing, and strategic interaction models are borne out by micro-level data on price changes. In particular, while menu cost models suggest the probability of a price change should only depend on the current gap, models with information-processing delays (or 'sticky information') and models with strategic interactions imply otherwise. For instance, information-processing delays suggest a negative correlation between current and lagged probabilities of price adjustment as firms do not continuously update their production plans due to the cost of acquiring and processing information. Hence a firm that recently incurred these costs and changed its price is not likely to do so in the near future. In contrast, strategic interactions motivated by the idea of a 'fair price' suggest a positive correlation (Rotemberg, 2005, 2006). If consumers feel they are entitled to their 'reference price' and firms are entitled to a 'reference profit', the probability of a price change should depend positively on the history of price changes. In other words, firms and consumers feel entitled to what they received in the past.

In this paper, we test these alternative models of price stickiness based on the daily pattern of price adjustment of nine Philadelphia gasoline wholesalers. This dataset provides a good testing ground for various reasons. First, wholesale gasoline is a physically homogeneous good, which has the advantage of controlling for the influence of product heterogeneity in pricing decisions, In addition, by focusing on wholesalers in a single city (Philadelphia), we minimize the impact of changes in transportation costs and taxes on the pattern of price adjustment. Second, changes in the upstream price of wholesale gasoline are observable. The cash price of bulk unleaded gasoline delivered to the New York Harbor (the main input cost of wholesale gasoline) is quoted in the New York Mercantile Exchange (NYMEX). Third, changes in wholesale gasoline (downstream) prices take place only at particular points in time (i.e., over $40 \%$ of the days in our sample), and often remain unchanged in the face of observable cost changes. Price stickiness is thus evident since changes in wholesale prices are discrete, despite fundamentals (e.g., the upstream price) changing continuously. Fourth, since wholesale gasoline is sold in standardized lots of one gallon, suppliers cannot simply reduce quantity in lieu of increasing price. Finally, changes in wholesale gasoline prices appear to have distinct dynamics, with price movements being more likely followed by movements in the same direction (see Table I). This positive correlation suggests past firm behavior may play an important role in explaining price stickiness.

Our work extends Davis and Hamilton's (2004) investigation of price stickiness in Philadelphia's wholesale gasoline market in two dimensions. First, to capture the discreteness in price changes and to allow for more general patterns of time dependence, we estimate an autoregressive conditional binomial (ACB) model. ${ }^{3}$ Specifically, we model the probability that a firm will change its price on day $t$ as a function of the historic distribution of price changes, past price change realizations, and the current and lagged gap between the wholesale price and the optimal price. In addition, by estimating the ACB jointly with the autoregressive conditional duration (ACD) model, we allow the probability to depend on the duration between price changes as purported by the autoregressive conditional hazard (ACH) model considered by Davis and Hamilton (2004). Whereas in the ACH model dynamics enter the probability of a price change only through the effect of past durations,

\footnotetext{
${ }^{3}$ Because the model is a binomial calendar time version of the autoregressive conditional multinomial model of Russell and Engle (2005), the model is called autoregressive conditional binomial. 
Table I. Description of price changes

\begin{tabular}{lccccc}
\hline Firm & $\begin{array}{c}\text { Number of } \\
\text { price changes }\end{array}$ & $\begin{array}{c}\text { Increase following } \\
\text { previous increase }\end{array}$ & $\begin{array}{c}\text { Increase following } \\
\text { previous decrease }\end{array}$ & $\begin{array}{c}\text { Decrease following } \\
\text { previous increase }\end{array}$ & $\begin{array}{c}\text { Decrease following } \\
\text { previous decrease }\end{array}$ \\
\hline 1 & 270 & 102 & 22 & 23 & 122 \\
2 & 361 & 124 & 42 & 43 & 151 \\
3 & 446 & 122 & 68 & 67 & 188 \\
4 & 236 & 98 & 20 & 21 & 96 \\
5 & 378 & 134 & 47 & 48 & 148 \\
6 & 304 & 117 & 28 & 28 & 130 \\
7 & 349 & 126 & 34 & 35 & 157 \\
8 & 350 & 139 & 26 & 27 & 124 \\
9 & 273 & 104 & 22 & 22 & \\
\hline
\end{tabular}

Note: The total number of increases and decreases (columns 3-6) sums to one less than the number of price changes (column 2) because there is no way to know whether the first price change observed in the dataset followed a price increase or decrease.

in the ACB-ACD model dynamics also enter via the historic distribution of the data and past realizations. Furthermore, the ACB model nests the logit model, thus allowing us to directly test whether the probability of a price change reflects the history of price adjustments through channels other than the current price-cost gap. In fact, contrary to Davis and Hamilton (2004), we find significant evidence that the history of price changes plays a key role in accounting for price stickiness, beyond what the current price gap would explain. Specifically, the autoregressive component of the ACB model is significant at a 5\% level for all firms, and the lag of the price gap is significant at a 5\% level for all but one firm. In contrast, the duration between price changes is rarely significant.

Second, Davis and Hamilton (2004) find that Dixit's (1991) menu cost model, which assumes a fixed cost of changing the price, is 'broadly consistent' with the data, as only the current value of the price-cost gap is relevant in predicting when a price change will occur. By estimating an atheoretical logit model and the ACH model, they find almost no support for two alternative theoretical explanations: partial price adjustment (Rotemberg, 1982) and information-processing delays (Calvo, 1983). Yet, since they find evidence of asymmetry as well, Davis and Hamilton (2004) conclude that price stickiness results from strategic considerations as to how competitors and customers will react to a price change. We extend their investigation by directly examining the testable implications of three alternative theories of price stickiness: (a) information-processing due to 'inattentive consumers' (Reis, 2006a); (b) information-processing due to 'inattentive producers' (Reis, 2006b); and (c) strategic interactions related to fair pricing (Rotemberg, 2005, 2006).

Our results have implications regarding which of the three explanations (menu costs, information-processing, or strategic interactions) best fits the observed wholesale gasoline data. The positive and significant effect of the historic distribution of price changes leads us to reject menu costs and information-processing delays as explanations for price stickiness. In contrast, this result, coupled with the finding that wholesalers are more likely to make large price decreases over large price increases and that cost shocks are immediately passed through to consumers, suggest that strategic considerations, possibly linked to the idea of 'fair pricing' in Kahneman et al. (1986) and Rotemberg $(2005,2006)$, play an important role in accounting for price stickiness.

The paper is organized as follows. Section 2 briefly discusses the theoretical models of price stickiness and their implications for the pattern of price adjustments. Section 3 describes the data 
and the structure of the wholesale gasoline market. Section 4 introduces the empirical methodology and discusses the predictions that can be tested using the ACB model. Section 5 presents the empirical results. Section 6 compares our results to previous work, and Section 7 concludes.

\section{THEORETICAL BACKGROUND}

Menu cost models such as Barro (1972), Sheshinski and Weiss (1977, 1983), and Dixit (1991) posit that there exists a fixed cost a firm must pay in order to adjust its price. The classic example is a restaurant having to print new menus if it wants to change the price of the food it serves (hence the name). Menu cost models assume that the physical act of changing the posted price is costly to the firm. The implication is that unless the additional profit received from a price change is greater than the cost of changing the price, the firm will elect to leave its price unchanged (Mankiw, 1985). Although menu costs are usually estimated to be quite small (e.g., Levy et al., 1997 , measure them to be $0.70 \%$ of total revenues for supermarket chains), they can exert a large impact on the business cycle (Mankiw, 1985), especially in the face of large cost shocks (Fishman and Simhon, 2005). ${ }^{4}$

Alternatively, theories proposed recently by Sims (1998, 2003) and Mankiw and Reis (2002) contend that the costly gathering, absorbing, and processing of information may explain why prices adjust infrequently or do not react to every change in market conditions. In Sims' (1998) setup, limited information-processing capacity stems from the fact that individuals and firms have a limited amount of time they can devote to gathering and analyzing data. Hence individuals and firms are inattentive to changes in market conditions (especially to macro shocks), which results in delayed responses to market signals. This implies that firms with frequent price changes should respond strongly to older information and weakly to newer information. Mankiw and Reis (2002), on the other hand, assume that only a fraction of firms receive information on the state of the economy and adjust prices accordingly. Here, the slow diffusion of information among the population stems from costs of acquiring information as well as costs of reoptimization. Thus 'sticky information' suggests a firm's probability of changing the price on consecutive days is low.

Recent theoretical work on the micro foundations of 'rational inattention' distinguish between 'inattentive' producers (Reis, 2006b) and consumers (Reis, 2006a). Rational inattention by producers suggests that firms do not continuously update their production plans. Instead, producers choose a price for their output and then derive an optimal time at which to be inattentive. Once the inattentive period is over, the producer then reoptimizes. While producers are inattentive, they receive no news about the economy until it is time to plan again. As above, the firm's probability of changing its price on consecutive days is low. Additionally, an implication of this model is that it predicts no asymmetry in the response to cost shocks. Since price setters are not aware of new information as it arrives, they cannot respond asymmetrically to it (see Reis, 2006b).

Rational inattention by consumers suggests that time-constrained consumers would rationally choose to update their information sporadically. The version relevant to wholesale prices is put forth by Ray et al. (2006). They show that in a model where menu costs increase as one moves to successively lower positions in the supply chain wholesalers have an incentive to price asymmetrically 'in the small' because the menu cost precludes the retailers from matching the increase. As a result, retailers do not pay attention (are inattentive) to small price increases.

\footnotetext{
${ }^{4}$ We refer the reader to Davis and Hamilton (2004) for a discussion and estimation of the Dixit (1991) menu cost model. 
Clearly, there is no incentive to price asymmetrically 'in the large', as a large price increase can be matched.

Finally, a third explanation for price stickiness stems from the importance of strategic interactions between a firm and its consumers. In particular, if consumers retaliate after a firm increases its price, the firm will be less likely to increase its price when it falls below what is optimal, even in the absence of a menu cost. In this vein, Rotemberg (1982) proposes that firms may deliberately stretch out a large price change over a successive string of smaller price changes in order to avoid upsetting consumers. This would result in prices adjusting slowly to cost shocks, with the adjustment taking place over an extended period of time.

On the other hand, 'fair pricing' theories suggest markets may fail to clear immediately as firms hesitate to raise prices 'unfairly' (Okun, 1981). In particular, Rotemberg's $(2005,2006)$ models of inflation where price stickiness is linked to the idea of 'fair pricing' can be traced to Kahneman et al.'s (1986) study on the importance of fairness in price setting. Kahneman et al. (1986) contend that, in long-term relationships, consumers feel they are entitled to their reference (past) price, but consumers also believe suppliers are entitled to their reference profit. When this reference profit is threatened, consumers deem it fair for a firm to raise its price at the consumers' expense, and even pass the complete loss onto them. However, consumers consider it unfair for a firm to take advantage of an increase in demand by raising its price. In addition, consumers believe it is unfair for a firm to ration shortages by raising its price, as both of these actions result in an 'unfair' windfall for the firm (profit over and above the firm's reference profit). In short, absent a cost shock, consumers believe that maintaining the status quo is fair.

\section{EMPIRICAL METHODOLOGY}

\subsection{ACB}

To test the competing theories of price adjustment, we utilize the ACB model. Define the probability that the firm changes its price on day $t+1$ as

$$
h_{t+1} \equiv \operatorname{Pr}\left(x_{t+1}=1 \mid x_{t}, x_{t-1}, \ldots, x_{1}, \mathbf{z}_{t}\right)
$$

where $x_{t+1}$ takes the value of unity if a price change is observed on day $t+1$. Then the $\operatorname{ACB}(\mathrm{q}, \mathrm{r}, \mathrm{s})$ model is defined as

$$
G^{-1}\left(h_{t+1}\right)=\omega+\sum_{j=1}^{q} \alpha_{j}\left(x_{t-j+1}-h_{t-j+1}\right)+\sum_{j=1}^{r} \beta_{j} G^{-1}\left(h_{t-j+1}\right)+\sum_{j=1}^{s} \delta_{j} x_{t-j+1}+\gamma \mathbf{z}_{t}
$$

where the probability of a price change is given by

$$
h_{t+1}=G\left[\omega+\sum_{j=1}^{q} \alpha_{j}\left(x_{t-j+1}-h_{t-j+1}\right)+\sum_{j=1}^{r} \beta_{j} G^{-1}\left(h_{t-j+1}\right)+\sum_{j=1}^{s} \delta_{j} x_{t-j+1}+\gamma \mathbf{z}_{t}\right]
$$

Thus, as can be seen in equation (3), the ACB model is a flexible specification that allows the probability of a price change on $t+1$ to depend on: (i) $q$ lags of the error term, $x_{t-j+1}-h_{t-j+1}$ (i.e., how close the past probabilities were to the actual outcomes); (ii) the history of probabilities 
of changes through $r$ lags of the link function $G^{-1}\left(h_{t+1}\right)$; (iii) the history of past changes through $s$ lags of the binary dependent variable $x_{t}$; and (iv) other predetermined variables $\mathbf{z}_{t}$. The function $G\left(h_{t+1}\right)$ is a strictly increasing continuous cumulative distribution function (hereafter c.d.f.) such as the standard normal or the logistic. Note that because changes in wholesale gasoline prices go into effect at midnight, we follow Davis and Hamilton's (2004; henceforth DH) notation and specify the probability of a price change in day $t+1$ as a function of the price gap observed on day $t$. Furthermore, since $G(\cdot)$ is strictly increasing, $G^{-1}\left(h_{t+1}\right)$ is a link function well defined by $G^{-1}\left(h_{t+1}\right)=y_{t} \Longleftrightarrow G\left(y_{t}\right)=h_{t+1}$. That is, $G^{-1}(\cdot)$ is a 1-1 mapping from $h_{t+1}$ to $\Re$.

Given initial conditions for $x_{t}$ and $h_{t}$, the path of price change probabilities can be constructed recursively and estimates for the parameters $\theta=\left\{w, \alpha_{1}, \ldots, \alpha_{q}, \beta_{1}, \ldots, \beta_{r}, \delta_{1}, \ldots, \delta_{s}\right\}$ obtained by maximizing the likelihood function

$$
\sum_{t=\max \{q, r, s\}+1}^{T-1}\left[x_{t+1} \log h_{t+1}+\left(1-x_{t+1}\right) \log \left(1-h_{t+1}\right)\right] .
$$

Define $P_{t}$ as the price charged by the firm at time $t$ and $P_{t}^{*}$ as the firm's optimal price. Following $\mathrm{DH}$, we define the optimal price as the firm's current price plus the average markup observed over the sample. Thus, if we assume that $G(\cdot)$ is the logistic c.d.f. - as we will do hereafter-and set $q=r=s=0$ and $\mathbf{z}_{t}=\left|P_{t}-P_{t}^{*}\right|$, the $\operatorname{ACB}(0,0,0)$ is equivalent to the atheoretical logit specification considered in $\mathrm{DH}$.

As in Russell and Engle (2005), we can incorporate the information regarding the duration between price changes in the ACB model. This is done by (a) including the logarithm of the contemporaneous duration, $u_{N(t)}$ (and possibly lags of it) as a covariate in equation (2); (b) modeling the expected duration process following Nelson's (1991) form ACD:

$$
\ln \left(\psi_{N(t)}\right)=\phi+\rho \frac{u_{N(t)-1}}{\psi_{N(t)-1}}+\xi \ln \left(\psi_{N(t)-1}\right)
$$

(or other ACD specification); and (c) estimating the ACB and ACD models simultaneously.

To test for the predictive power of the previous day's information, we follow DH by defining $\left|P_{t-1}-P_{t-1}^{*}\right|$ as the absolute value of the previous day's price gap. To test the idea of partial adjustment, define $\left|P_{w 1(t)}-P_{w 1(t)}^{*}\right|$ as the amount of the gap remaining after the most recent price change. Also, because competing theoretical explanations imply various predictions of asymmetry, we follow DH and allow for an asymmetric response by defining $\theta_{t}$ as a dummy variable taking on the value of unity if $P_{t}-P_{t}^{*} \geq 0$ and zero otherwise, and replace the constant $(\omega)$ and the vector of explanatory variables $\mathbf{z}_{t}=\left(\left|P_{t}-P_{t}^{*}\right|\right)^{\prime}$ with

$$
\mathbf{z}_{t}=\left[\theta_{t},\left(1-\theta_{t}\right), \theta_{t}\left(P_{t}-P_{t}^{*}\right),-\left(1-\theta_{t}\right)\left(P_{t}-P_{t}^{*}\right)\right]^{\prime}
$$

Separating the constant into a positive $\left(\theta_{t}\right)$ and a negative $\left(1-\theta_{t}\right)$ component addresses the question: Is the firm more (or less) likely to raise its price in response to a small negative gap than lower it in response to a small positive gap? Whereas separating the gap into the positive $\left(\theta_{t}\left(P_{t}-P_{t}^{*}\right)\right)$ and negative $\left(\left(1-\theta_{t}\right)\left(P_{t}-P_{t}^{*}\right)\right)$ elements addresses the question: Is the firm more (or less) likely to raise its price in response to a large negative gap than lower it in response to a large positive gap? 
The motivation for this ACB specification is threefold. First, the ACB model provides a flexible framework to analyze the role of menu costs, information-processing delays, and strategic interactions in the discreteness of price adjustments. For instance, if price stickiness is motivated by a physical menu cost or if there are no delays in processing information, neither lags of the price gap nor the previous history of price adjustments should enter significantly in the current probability of a price change. Second, because the ACB model nests the logit model, likelihood ratio tests regarding the relevance of the history of price changes are straightforward to compute. For instance, if we assume that $G(\cdot)$ is the logistic c.d.f. and we use an $\operatorname{ACB}(0,1,1)$ specification, testing that 'the history of prices matters for the probability of a price change only through the current value of the price gap' ( $\mathrm{DH}$, p. 31) amounts to testing whether $\beta=\delta=0$. Finally, by estimating the ACB-ACD model in the fashion just described, we can directly test the effect of the duration process on the probability of a price change. Furthermore, whereas a zero effect of lagged durations in the ACH model precludes any effect of the history of price changes - other than through the current value of the gap (see Section 6.2) - it does not in the ACB-ACD. Thus the latter allows for more general forms of time dependence.

\subsection{Testable Predictions}

Given data on price and cost, we argue that certain empirical regularities should be observed under each of the models discussed in Section 2..$^{5}$ As a result, we can derive the following testable implications (see also Table II):

- Menu cost (or 'broadly consistent' with a menu cost): $\beta=\delta=0$. Neither the past history of price adjustments nor the past distribution of price changes should affect the probability of observing a price change. That is, the probability of a price change should depend only on the current value of the price gap. ${ }^{6}$ For this reason, the estimated coefficients on $\left|P_{t-1}-P_{t-1}^{*}\right|$ and $\left|P_{w 1(t)}-P_{w 1(t)}^{*}\right|$ should not be statistically different from zero. Also, we should observe no asymmetry in the small' or 'in the large'. In other words, $\theta_{t}=\left(1-\theta_{t}\right)$ and $\theta_{t}\left(P_{t}-P_{t}^{*}\right)=-\left(1-\theta_{t}\right)\left(P_{t}-P_{t}^{*}\right)$, as the only relevant consideration is whether or not the additional profit resulting from a price

Table II. Testable implications in the ACB framework: effect on the probability of a price change

\begin{tabular}{llccc}
\hline & $\begin{array}{c}\text { Autocorrelation } \\
G^{-1}\left(h_{t-1}\right)\end{array}$ & $\begin{array}{c}\text { History of price changes } \\
x_{t-1}\end{array}$ & $\begin{array}{c}\text { Remaining price gap } \\
\left|P_{w 1(t)}-P_{w 1(t)}^{*}\right|\end{array}$ & Symmetry \\
\hline Menu costs & No effect $(\beta=0)$ & No effect $(\delta=0)$ & No effect & Yes \\
Information processing & Negative $(\beta<0)$ & Negative $(\delta<0)$ & No effect & Yes \\
'Inattentive producers' & Negative $(\beta<0)$ & Negative $(\delta<0)$ & No effect & Not in the 'small' \\
'Inattentive consumers' & Negative $(\beta<0)$ & Negative $(\delta<0)$ & No effect & Positive \\
Strategic interactions & Positive $(\beta>0)$ & Positive $(\delta>0)$ & No effect & Not in the 'large' \\
Partial adjustment & Positive $(\beta>0)$ & Positive $(\delta>0)$ & Positive $(\delta>0)$ & \\
Fair pricing & Positive $(\beta>0)$ & & &
\end{tabular}

\footnotetext{
${ }^{5}$ If fact, this is a common way to carry out a test. For example, Lewis (2003) estimates a vector error correction model to see if the pattern of adjustment is consistent with his 'reference price search model', and Tappata (2008) conducts a rank reversal test and a Kolmogorov-Smirnov equality of distributions test to see if the results are consistent with the predictions of his model of price dispersion.

${ }^{6}$ See Dixit (1991), Barro (1972), Sheshinski and Weiss (1977, 1983), and Mankiw (1985).
} 
change is greater than the menu cost. ${ }^{7}$ Note that, as in Reis (2006a), we interpret menu costs as the physical cost of changing the posted price.

- Information processing delays: The probability of a price change should exhibit negative autocorrelation $(\beta<0)$, as periods with high probability of a price change should be followed by periods where this probability is low. Likewise, if a firm changed its price yesterday, it is less likely to do so again today $(\delta<0)$. Furthermore, since firms react more strongly to past than current information, the coefficient on $\left|P_{t-1}-P_{t-1}^{*}\right|$ should be positive and significant, indicating that a large gap yesterday will increase the probability of a price change today.

- Rational inattention by producers: The probability of a price change should exhibit autocorrelation, as the next time a firm changes its price depends on the time since the last price change. Additionally, if a firm changes its price today, it is likely to be inattentive the following day $(\delta<0)$. The coefficient on $u_{N(t)}$ should be positive, indicating that as the time between price changes becomes larger the inattentiveness period draws to a close, increasing the probability of a price change. Finally, given the discussion in Section 2, we expect no asymmetry 'in the small' or 'in the large'. That is, $\theta_{t}=\left(1-\theta_{t}\right)$ and $\theta_{t}\left(P_{t}-P_{t}^{*}\right)=-\left(1-\theta_{t}\right)\left(P_{t}-P_{t}^{*}\right)$.

- Rational inattention by consumers: Asymmetry 'in the small' with $\left(1-\theta_{t}\right)>\theta_{t}$ should occur if consumers are inattentive to small price changes. That is, a firm is more likely to increase its price in response to a small negative gap than lower it in response to a small positive one. No asymmetry 'in the large' $\left(\theta_{t}\left(P_{t}-P_{t}^{*}\right)=-\left(1-\theta_{t}\right)\left(P_{t}-P_{t}^{*}\right)\right)$.

- Partial adjustment: The probability of a price change should exhibit positive autocorrelation $(\beta>0)$, since firms prefer a series of smaller price changes over a large one-time change. Likewise, we should expect $\delta>0$ since firms are likely to make price changes on successive days. As previously discussed, the coefficient on the amount of the gap remaining after the most recent price change, $\left|P_{w 1(t)}-P_{w 1(t)}^{*}\right|$, should be positive and significant.

- Fairness: Like partial adjustment, the probability of a price change should exhibit positive autocorrelation $(\beta>0)$. In this case, the correlation reflects the finding by Kahneman et al. (1986) that consumers feel entitled to their reference price (the price they received in the immediate past). Similarly, price changes should be immediately passed through from wholesalers to retailers. Thus, $\left|P_{w 1(t)}-P_{w 1(t)}^{*}\right|$ should contain no additional predictive power for a price change. Given that retailers believe that large price increases may be unfair, we should expect to see asymmetry 'in the large' in the form of $-\left(1-\theta_{t}\right)\left(P_{t}-P_{t}^{*}\right)<\theta_{t}\left(P_{t}-P_{t}^{*}\right)$, meaning a firm is more likely to make a large price decrease over a large price increase.

Two caveats are in order here. ${ }^{8}$ First, there is no reason to rule out a priori the possibility of multiple explanations being consistent with the observed pattern of price adjustment. For instance, a producer could face an information-processing delay and then have to pay a menu cost on top of that. Second, although theoretical menu cost models, including those considered here, assume symmetry, it may be possible for a firm to face an asymmetric menu cost. The key point is that there is no clear intuitive reason why gasoline wholesalers would face a menu cost (defined as the cost of physically changing the posted price) that was different depending on the direction of

\footnotetext{
${ }^{7}$ Specifically, the firm in Dixit (1991) minimizes the expected value of the square deviation of the price from the optimal price. Consequently, there is symmetry in the response to cost increases and decreases. Furthermore, note that dynamics in menu cost models can be generated by the presence of inventories (Aguirregabiria, 1999) or stocks of goodwill (Slade, 1998) in addition to the physical menu cost.

${ }^{8} \mathrm{We}$ are thankful to a referee for pointing this out to us.
} 
the price change. However, in practice, they might change their prices asymmetrically because of a different motivation (such as rational consumer inattention) and then bear a menu cost. ${ }^{9}$

\section{DATA}

We use daily data for nine wholesale gasoline firms in Philadelphia and, as a measure of upstream prices, the NYMEX price quoted for bulk unleaded gasoline. Because New York Harbor is the logistic hub for refined gasoline both arriving by pipeline from the Gulf Coast and from abroad by tanker (Trench, 2001), the cash price of bulk unleaded gasoline delivered to New York Harbor represents a good proxy for the input cost (on average, $96 \%$ of the wholesale price is represented by the cost of gasoline at the hub). ${ }^{10}$ The data are measured in cents per gallon and span the period between 1 January 1989 and 31 December 1991. The wholesale data were originally collected by the Oil Pricing Information Service (http://opisnet.com) and made available to us by DH. ${ }^{11}$

Table III presents summary statistics for the nine wholesale firms in the dataset. Although all the wholesalers in the sample sell gasoline containing familiar brand names, it is worth noting that BP (firm 3) sells unbranded gasoline. A branded retail station must obtain its gasoline from a wholesaler who sells that particular brand, whereas an unbranded retail station can buy its gasoline from any wholesaler it wants, as long as it does not advertise that it sells a brand. Often, a contract will tie a retailer to a specific wholesaler for a length of time of 'one day to one year' (Majority Staff on the Permanent Senate Subcommittee on Investigations, 2002). Wholesale price stickiness is illustrated by the frequencies of changes in the wholesale price relative to the NYMEX price. Whereas the NYMEX price changed nearly everyday (frequency $=0.95$ ), with the exception of BP (frequency $=0.57$ ), the firms changed the wholesale price less than $50 \%$ of the days in the sample.

To get a sense of how wholesale gasoline prices behave relative to other prices, it is useful to compare our data to the data analyzed by Bils and Klenow (2004). Using monthly data from the Bureau of Labor Statistics from 1995 to 1997, Bils and Klenow (2004) find that retail gasoline prices are adjusted more frequently than the other 350 final goods examined. They compute an average duration of 0.6 for price changes in retail gasoline (see Appendix Table in Bils and Klenow), which corresponds to an average duration of 18 days for a 30-day month. This is comparable to the average duration between price changes in Newburgh's retail stations between 1 January 1999 and 31 December 2000 (Davis, 2007), which is 10 days. As one would expect, wholesale price changes far more often, with the average duration between price changes being only 2.4 days in our dataset.

Of interest also are the frequencies and average magnitudes of price increases and decreases (see Table III). Note that whereas increases in the wholesale price are less likely than decreases, the frequency of increases and decreases in the NYMEX price is almost identical $(0.48$ and 0.46 , respectively). The summary statistics suggest that wholesalers are more likely to decrease their price than increase it, despite the fact that the input cost is about equally likely to increase or

\footnotetext{
${ }^{9}$ In fact, Davis (2007) found evidence of menu costs in retail gasoline prices. But since he also found evidence of asymmetry, he concluded that price stickiness in retail gasoline prices resulted from consumers' search costs (consumers not being able to instantly observe prices at all stations) and menu cost on behalf of the retail stations.

${ }^{10}$ For a thorough overview of the gasoline market, see Borenstein et al. (1997).

${ }^{11}$ We are thankful to Michael Davis and Jim Hamilton for making the data publicly available through the Journal of Money, Credit, and Banking data archive (http://economics.sbs.ohio-state.edu/jmcb/jmcb/02199/02199.zip).
} 
Table III. Summary statistics

\begin{tabular}{lccccccccc}
\hline Firm & Brand & $\begin{array}{c}\text { Number of } \\
\text { observations }\end{array}$ & $\begin{array}{c}\text { Average } \\
\text { price }\end{array}$ & $\begin{array}{c}\text { Average } \\
\text { markUp }\end{array}$ & $\begin{array}{c}\text { Frequency of } \\
\text { price change }\end{array}$ & $\begin{array}{c}\text { Frequency of } \\
\text { price increase }\end{array}$ & $\begin{array}{c}\text { Frequency of } \\
\text { price decrease }\end{array}$ & $\begin{array}{c}\text { Average } \\
\text { increase }\end{array}$ & $\begin{array}{c}\text { Average } \\
\text { decrease }\end{array}$ \\
\hline 1 & Amoco & 782 & 69.8 & 4.25 & 0.35 & 0.16 & 0.19 & 0.87 & 0.70 \\
2 & ARCO & 782 & 67.6 & 2.12 & 0.46 & 0.21 & 0.25 & 0.85 & 0.70 \\
3 & BP & 782 & 67.3 & 1.81 & 0.57 & 0.24 & 0.33 & 1.42 & 1.03 \\
4 & Chevron & 641 & 68.8 & 2.82 & 0.37 & 0.19 & 0.18 & 0.95 & 0.81 \\
5 & Exxon & 782 & 68.3 & 2.78 & 0.48 & 0.23 & 0.25 & 0.83 & 0.74 \\
6 & Gulf & 743 & 69.6 & 3.74 & 0.41 & 0.2 & 0.21 & 0.87 & 0.70 \\
7 & Mobil & 779 & 68.9 & 3.40 & 0.45 & 0.21 & 0.24 & 0.82 & 0.65 \\
8 & Sunoco & 782 & 69.2 & 3.71 & 0.45 & 0.21 & 0.24 & 0.76 & 0.66 \\
9 & Texaco & 681 & 69.7 & 3.25 & 0.40 & 0.19 & 0.21 & 0.90 & 0.66 \\
& NYMEX & 782 & - & 65.1 & 0.95 & 0.48 & 0.46 & 1.36 & 1.39 \\
\hline
\end{tabular}

Note: Table reports summary statistics for the nine wholesale firms in the sample. The frequencies of price changes are the observed daily frequencies for the 1989-1991 period. The average price is in cents per gallon. The average markup is computed as the average difference between the wholesale price and the NYMEX price for bulk unleaded gasoline and is measured in cents per gallon. The average increase and decrease are measured in cents per gallon of unleaded gasoline.

decrease. Furthermore, note that the average magnitude of price decreases is smaller than the magnitude of price increases for all firms, which suggests that wholesale prices may respond asymmetrically to increases and decreases in the upstream price of gasoline.

\section{TIME DEPENDENCE AND THE HISTORY OF PRICE CHANGES}

\subsection{The Dynamics of Price Adjustment}

Estimation results for the $\mathrm{ACB}(0,1,1)$ model reported in Table IV suggest the presence of time dependence in seven out of the nine gasoline wholesalers in Philadelphia. ${ }^{12}$ A likelihood ratio test rejects the null hypothesis that $\beta$ and $\delta$ are jointly insignificant for seven of the nine firms. Note that the lagged price gap, $\left|P_{t-1}-P_{t-1}^{*}\right|$, is statistically significant for eight of the nine firms (see Table V). As for the distribution of past price changes, $\beta$, the coefficient on the lagged link function $G^{-1}\left(h_{t}\right)$ is significant at a $5 \%$ level for all firms, and $\delta$, the coefficient on the lagged indicator $x_{t}$, is statistically significant for firms 3, 4, 5 and 9. Moreover, we can reject the null hypothesis that $\beta=\delta=\gamma_{2}=0$, where $\gamma_{2}$ is the coefficient on $\left|P_{t-1}-P_{t-1}^{*}\right|$, at the $5 \%$ level for all but two firms. ${ }^{13}$ For the remaining two firms, firms 7 and 8 , the $p$-values for the likelihood ratio test are 0.099 and 0.114 , respectively. Thus the test results suggest that the $\mathrm{ACB}(0,1,1)$ - hereafter $\mathrm{ACB}$ - with current and lagged price gap fits the data better than the restricted logit for seven of the nine firms (see second to last column of Table IV).

To better understand the dynamics, let us take a closer look at the effects of the history of price changes and the price gap. First, for all firms except for firms 1 and 8 , the sign on $\beta$ is positive. Given that the link function $G^{-1}\left(h_{t}\right)$ is strictly increasing in $h_{t}$, this implies that an increase in

\footnotetext{
${ }^{12}$ A likelihood ratio test strongly rejects the $\operatorname{ACB}(1,1,1)$ in favor of the $\mathrm{ACB}(0,1,1)$ model for all firms. Additionally, for all firms but two, the Schwarz Bayesian Criterion (Schwarz, 1978) is lowest for the ACB $(0,1,1)$ over a specification with additional lags of $\beta$ and $\delta$. The $\mathrm{SBC}$ for firm 2 is only slightly lower for $\operatorname{ACB}(0,2,2)$ specification $(-546.08$ vs. -545.49$)$. For ease of comparison, we use an $\operatorname{ACB}(0,1,1)$ for all firms.

${ }^{13}$ Given that the regressors are stationary and the number of lags are enough to capture serial correlation, likelihood ratio tests are valid.
} 
Table IV. $\operatorname{ACB}(0,1,1)$ estimates with lagged gap included as additional explanatory variables

\begin{tabular}{ccccccccl}
\hline Firm & $\omega$ & $\beta$ & $\delta$ & $\left|P_{t}-P_{t}^{*}\right|$ & $\left|P_{t-1}-P_{t-1}^{*}\right|$ & $\log \mathrm{L}$ & $\mathrm{LR}$ & \multicolumn{2}{c}{ RV } \\
\hline 1 & -1.601 & $-0.505^{* *}$ & -0.184 & -0.0364 & $0.196^{* *}$ & -478.97 & $0.00070^{* *}$ & 1.82 \\
& $(0.234)$ & $(0.145)$ & $(0.151)$ & $(0.0386)$ & $(0.0402)$ & & 0.0344 \\
2 & -0.110 & $0.828^{* *}$ & 0.149 & $0.107^{* *}$ & $-0.102^{* *}$ & -529.43 & $0.0324^{*}$ & 0.968 \\
& $(0.0595)$ & $(0.117)$ & $(0.0802)$ & $(0.0350)$ & $(0.0331)$ & & 0.1665 \\
3 & -0.0898 & $0.368^{*}$ & $0.320^{*}$ & $0.296^{* *}$ & $-0.247^{* *}$ & -512.83 & $0.0000^{* *}$ & 2.33 \\
& $(0.0987)$ & $(0.174)$ & $(0.140)$ & $(0.0551)$ & $(0.0525)$ & & & 0.0099 \\
4 & -0.638 & $0.467^{*}$ & $0.508^{* *}$ & $0.106^{*}$ & -0.0680 & -405.37 & $0.00530^{* *}$ & 2.26 \\
& $(0.272)$ & $(0.239)$ & $(0.174)$ & $(0.0433)$ & $(0.0581)$ & & & 0.0119 \\
5 & -0.0992 & $0.901^{* *}$ & $0.202^{* *}$ & $0.113^{* *}$ & $-0.114^{* *}$ & -520.52 & $0.0000^{* *}$ & 1.38 \\
& $(0.0513)$ & $(0.0464)$ & $(0.0900)$ & $(0.0296)$ & $(0.0292)$ & & 0.0838 \\
6 & -0.209 & $0.827^{* *}$ & 0.206 & $0.185^{* *}$ & $-0.169^{* *}$ & -471.30 & $0.0183^{*}$ & 3.45 \\
& $(0.129)$ & $(0.105)$ & $(0.121)$ & $(0.0333)$ & $(0.0352)$ & & 0.0003 \\
7 & -0.0672 & $0.899^{* *}$ & 0.0686 & $0.121^{* *}$ & $-0.117^{* *}$ & -521.19 & 0.1136 & 1.59 \\
& $(0.0507)$ & $(0.0608)$ & $(0.0696)$ & $(0.0276)$ & $(0.0267)$ & & & 0.0559 \\
8 & -0.868 & $-0.570^{*}$ & -0.00605 & 0.0223 & $0.126^{* *}$ & -524.31 & 0.0990 & 2.11 \\
& $(0.253)$ & $(0.256)$ & $(0.210)$ & $(0.0467)$ & $(0.0419)$ & & & 0.0174 \\
9 & -0.267 & $0.780^{* *}$ & $0.259^{*}$ & $0.157^{* *}$ & $-0.141^{* *}$ & -432.65 & $0.0186^{*}$ & 2.09 \\
& $(0.101)$ & $(0.0798)$ & $(0.115)$ & $(0.0321)$ & $(0.0330)$ & & & 0.0183 \\
& & & & & & & & \\
\hline
\end{tabular}

Note: LR reports the $p$-value from the likelihood ratio test of the null hypothesis that this ACB specification reduces to the logit with only the current gap. RV reports the Rivers and Vuong (2002) test statistic for the test of the ACH vs. the ACB ( $p$-value reported underneath the statistic). Asterisks indicate statistical significance at the ${ }^{*} 5 \%$ and ${ }^{* *} 1 \%$ level. Standard errors in parentheses.

the probability of a price change at time $t$ would lead to an increase in the probability at $t+1$, $h_{t+1}$. For these firms, an increase in the absolute value of the current price gap implies a larger probability of a price change $\left(\gamma_{1}>0\right)$, and a higher lagged gap implies a decrease in the probability of a price change $\left(\gamma_{2}<0\right)$. Second, for firms 1 and 8 , where $\beta$ is negative, information regarding the price gap is processed with a longer delay. Note that for these two firms $\gamma_{1}$ is not statistically different from zero, but $\gamma_{2}$ is positive and significant. Lastly, regarding the realizations of price changes, less than half of the firms are more likely to adjust the price in $t+1$ if they changed it in $t(\delta>0)$.

To illustrate the dynamics in both the $\mathrm{ACB}$ and the logit $(\operatorname{ACB}(0,0,0))$, we simulate how the probability of a price change responds to a one-time $10 \not k$ increase in the price gap. These simulations can be interpreted as the dynamic response to an unexpected $10 \not c$ increase in the NYMEX price of gasoline while holding the desired markup for each firm constant, assuming the probability of a price change in the previous periods was equal to the steady-state probability and the price gap was equal to the average value observed in the sample. ${ }^{14}$ The simulations are calculated in the following manner. First, we assume the probability of a price change at time $t=0$ is equal to the steady-state probability in the $\operatorname{ACB}(0,1,1)$ model, $\bar{h}$. To obtain this steady-state probability of a price change we solve equation (2) for $G^{-1}(\bar{h})$, which gives

$$
G^{-1}(\bar{h})=\frac{\omega+\gamma \overline{\mathbf{z}}}{1-\beta}
$$

\footnotetext{
${ }^{14}$ A $10 \not c$ shock corresponds to the maximum NYMEX increase observed in the dataset, which occurred on 25 October 1990, possibly in response to increased fear of war and long-term supply disruptions when Saddam Hussein threatened Israel on 9 October.
} 
Table V. Test for significance of additional variables

\begin{tabular}{|c|c|c|c|c|c|}
\hline Firm & $\left|P_{t-1}-P_{t-1}^{*}\right|$ & $\left|P_{w 1(t)}-P_{w 1(t)}^{*}\right|$ & $\left\{\theta_{t}, P_{t}-P_{t}^{*}\right\}$ & $u_{N(t-1)-1}$ & $y_{t-1}^{\text {other }}$ \\
\hline \multicolumn{6}{|l|}{ Logit } \\
\hline 1 & $0.006^{*}$ & 0.283 & $0.035^{*}$ & & \\
\hline 2 & 0.083 & 0.485 & $0.000^{* *}$ & & \\
\hline 3 & $0.000^{* *}$ & 0.294 & 0.265 & & \\
\hline 4 & 0.280 & 0.488 & $0.000^{* *}$ & & \\
\hline 5 & 0.354 & 0.753 & 0.511 & & \\
\hline 6 & 0.237 & 0.642 & $0.000^{* *}$ & & \\
\hline 7 & 0.842 & 0.642 & 0.235 & & \\
\hline 8 & 0.147 & 0.573 & 0.188 & & \\
\hline 9 & 0.963 & 0.417 & 0.056 & & \\
\hline \multicolumn{6}{|l|}{$A C H$} \\
\hline 1 & $0.036^{*}$ & 0.907 & $0.005^{* *}$ & $0.000^{* *}$ & \\
\hline 2 & 0.428 & 0.261 & $0.037^{*}$ & 0.059 & \\
\hline 3 & $0.001^{* *}$ & 0.656 & $0.018^{*}$ & 0.393 & \\
\hline 4 & 0.082 & 0.426 & $0.000^{* *}$ & 0.458 & \\
\hline 5 & 0.611 & 0.872 & 0.425 & $0.000^{* *}$ & \\
\hline 6 & 0.237 & 0.949 & $0.000^{* *}$ & 0.171 & \\
\hline 7 & 0.576 & 0.522 & 0.067 & 0.632 & \\
\hline 8 & 0.139 & 0.443 & 0.061 & 0.573 & \\
\hline 9 & 0.474 & 0.833 & $0.001^{* *}$ & 0.057 & \\
\hline \multicolumn{6}{|l|}{$A C B$} \\
\hline 1 & $0.0002^{* *}$ & 0.3482 & $0.0257^{*}$ & & $0.0000^{* *}$ \\
\hline 2 & $0.0348^{*}$ & 0.6390 & $0.0022^{* *}$ & & $0.0173^{*}$ \\
\hline 3 & $0.0004^{* *}$ & 0.6390 & 0.5273 & & 0.2687 \\
\hline 4 & 0.2741 & 0.0769 & $0.0003^{* *}$ & & $0.0000^{* *}$ \\
\hline 5 & $0.0000^{* *}$ & 0.0931 & 0.7445 & & 0.1517 \\
\hline 6 & 0.1565 & 0.1345 & $0.0002^{* *}$ & & $0.0000^{* *}$ \\
\hline 7 & $0.0181^{*}$ & 0.7290 & 0.2725 & & $0.0000^{* *}$ \\
\hline 8 & $0.0355^{*}$ & 1.0000 & 0.1281 & & $0.0001^{* *}$ \\
\hline 9 & $0.0024^{* *}$ & 0.2453 & 0.0537 & & 0.4371 \\
\hline
\end{tabular}

Note: Table reports $p$-value of test of null hypothesis that the indicated variable does not belong as an additional explanatory variable to the logit or $\mathrm{ACH}$ model. Asterisks $\left(^{*}\right)$ indicate statistical significance at the $* 5 \%$ level and ${ }^{* *} 1 \%$ level.

where $\overline{\mathbf{z}}$ contains the averages of $\left|P_{t}-P_{t}^{*}\right|$ and $\left|P_{t-1}-P_{t-1}^{*}\right|$ and $x_{t}=0 .{ }^{15}$ Then we replace this value for $G^{-1}(\bar{h})$ in our $\operatorname{ACB}(0,1,1)$ specification to obtain

$$
\begin{aligned}
\bar{h} & =G\left[\omega+\beta G^{-1}(\bar{h})+\gamma_{1}\left|\overline{P_{t}-P_{t}^{*}}\right|+\gamma_{2}\left|\overline{P_{t-1}-P_{t-1}^{*}}\right|\right] \\
& =G\left[\omega+\beta G^{-1}(\bar{h})+\left(\gamma_{1}+\gamma_{2}\right)\left|\overline{P-P^{*}}\right|\right]
\end{aligned}
$$

Second, we assume that at time $t=1$ the price gap experiences a $10 \not c$ one-time increase over the sample average so that $\left|P_{1}-P_{1}^{*}\right|=\left|\overline{P-P^{*}}\right|+10$. We then assume that the firm adjusts its price so as to set $\left|P_{t}-P_{t}^{*}\right|=\left|\overline{P-P^{*}}\right|$ for $t \geq 2$ (the price change enters in effect at midnight of day 1$)$ and there are no further shocks or price adjustments in the forecast horizon $\left(x_{2}=1, x_{t}=0\right.$

${ }^{15}$ For ease of comparison of the dynamics in the ACB and the logit model, we assume that at time $t=1$ the price gap is positive. However, the dynamic responses are unchanged if we start from a zero gap. That is to say, if the wholesaler is pricing at the optimal price. 
for $t \neq 2)$. Thus, the probability of a price change for the $\operatorname{ACB}(0,1,1)$ specification is

$$
h_{t}=\left\{\begin{array}{c}
G\left[\omega+\beta G^{-1}(\bar{h})+\gamma_{1}\left(\left|\overline{P-P^{*}}\right|+10\right)+\gamma_{2}\left|\overline{P-P^{*}}\right|\right] \text { for } t=1 \\
G\left[\omega+\beta G^{-1}\left(h_{t-1}\right)+\delta+\gamma_{1}\left|\overline{P-P^{*}}\right|+\gamma_{2}\left(\left|\overline{P-P^{*}}\right|+10\right)\right] \text { for } t=2 \\
G\left[\omega+\beta G^{-1}\left(h_{t-1}\right)+\left(\gamma_{1}+\gamma_{2}\right)\left|\overline{P-P^{*}}\right|\right] \text { for } t>2
\end{array}\right\}
$$

The response probability for the logit model can be computed by setting $\beta=\delta=0$. Therefore the simulated probability is given by ${ }^{16}$

$$
h_{t}=\left\{\begin{array}{c}
G\left[\widetilde{\omega}+\widetilde{\gamma_{1}}\left(\left|\overline{P_{t}-P_{t}^{*}}\right|+10\right)\right] \text { for } t=1 \\
G\left[\widetilde{\omega}+\widetilde{\gamma_{1}}\left|\overline{P-P^{*}}\right|\right] \text { for } t \geq 2
\end{array}\right\}
$$

where a tilde $(\sim)$ denotes the estimated parameters in the logit specification.

To compare the response probabilities implied by the ACB and the logit, we plot these simulations in Figure 1. For firms with $\beta>0$, the pattern of adjustment implied by the ACB and the logit are generally similar. ${ }^{17}$ The probability of a price change rises immediately after the shock and then quickly returns to the initial level, suggesting that one price increase takes place following the shock. Note in Table IV that, for some of the firms, the coefficients on the current and lagged price gap are roughly equal and of opposite sign. This allows for the price change probability to immediately return to steady state following a price change. In addition, for firm 3, the probability of a price change drops considerably after the price has been adjusted. Interestingly, this firm (BP) is the only wholesaler identified as selling unbranded gasoline in the sample. ${ }^{18}$ This is suggestive evidence that unbranded dealers compete more intensely than branded dealers (Hastings, 2004; Borenstein et al., 1997). For firms 1 and 8, where $\beta<0$, informationprocessing delays are apparent. The increase in the probability of a price change takes place only after one day rather than immediately after the shock.

Note that the magnitude of the shock used in the simulation is an order of magnitude higher than the average price increase in the NYMEX price $(1.36 \not c)$. Using such a large shock has the advantage of facilitating the comparison between the dynamics implied by the ACB and the logit model. However, to get a better grasp on the dynamics of price adjustment implied by the ACB, it is worth contrasting the response to an average $1.36 \not c$ cost increase with the response to the $10 \not k$ shock. Figure 2 illustrates how the probability that a firm will change its price evolves in these two instances. Note how for all firms but firm 3 (the unbranded wholesaler) the probability remains below $50 \%$ for an average cost increase, reflecting price stickiness.

Another scenario worth exploring is what happens if the firm does not immediately increase its price in response to the shock. As before, for ease of illustration, we use a $10 \not k$ shock. In this case, the response probabilities for the ACB and the logit, respectively, would be given by

$$
h_{t}=\left\{\begin{array}{c}
G\left[\omega+\beta G^{-1}(\bar{h})+\gamma_{1}\left(\left|\overline{P-P^{*}}\right|+10\right)+\gamma_{2}\left|\overline{P-P^{*}}\right|\right] \quad \text { for } t=1 \\
G\left[\omega+\beta G^{-1}\left(h_{t-1}\right)+\gamma_{1}\left(\left|\overline{P-P^{*}}\right|+10\right)+\gamma_{2}\left(\left|\overline{P-P^{*}}\right|+10\right)\right] \text { for } t \geq 2
\end{array}\right\}
$$

\footnotetext{
${ }^{16}$ Recall that in the logit the lagged price gap is not significantly different from zero for seven out of nine firms. Yet the results are similar if we include the lagged gap.

${ }^{17}$ A difference between the ACB and the logit responses is that for the majority of the firms the steady-state probability of a price change is lower for the ACB. These differences result from the formulas used to compute the steady state in the logit (equation (10)) and the ACB (equation (9)) models.

${ }^{18}$ Most wholesalers participate in both the branded and unbranded market, quoting a daily price for each type of wholesale gasoline. The OPIS dataset clearly indicates if the daily price observation is for the wholesaler's branded or unbranded gasoline. For all wholesalers but BP, the branded observations yielded a more complete dataset to be used in the analysis.
} 

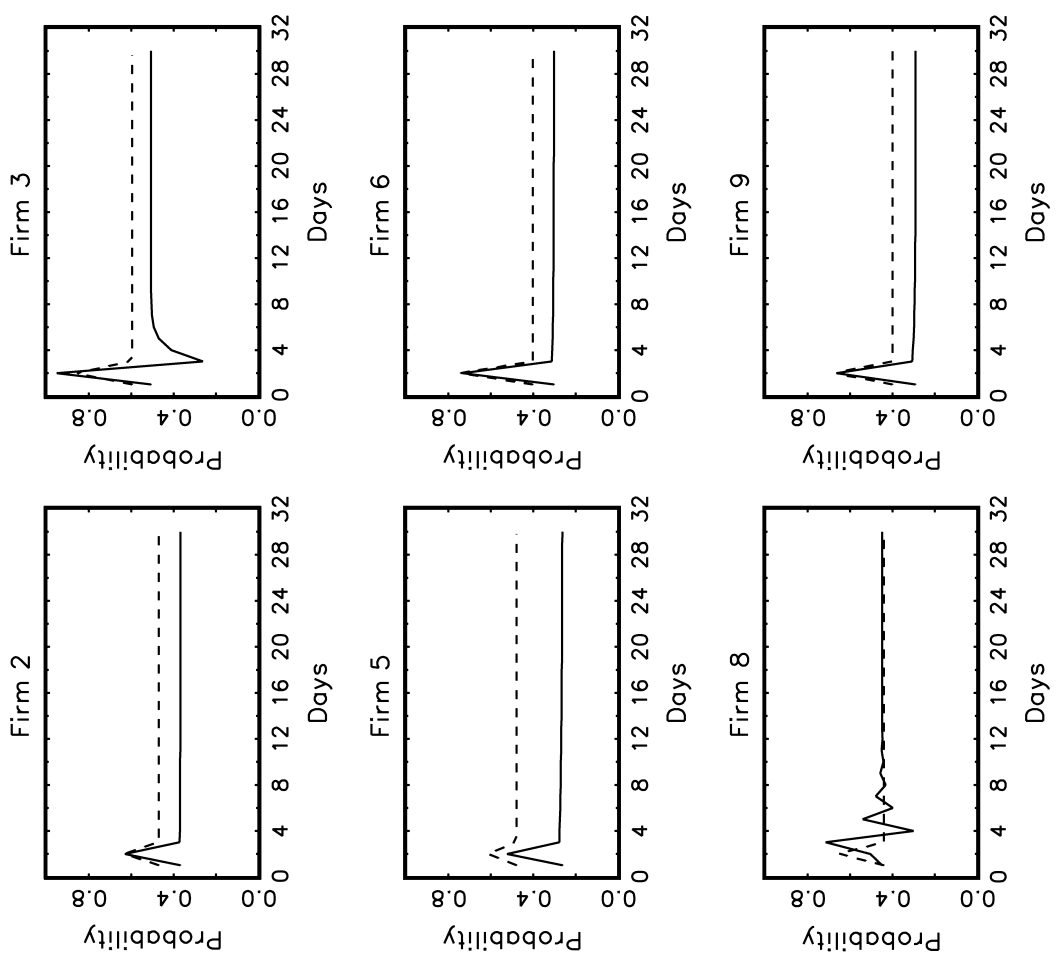

0
0
0
0
0
0
0
0
0
0
0
0
0
0
0
0
0
0
0
0
0
0
0
0
0
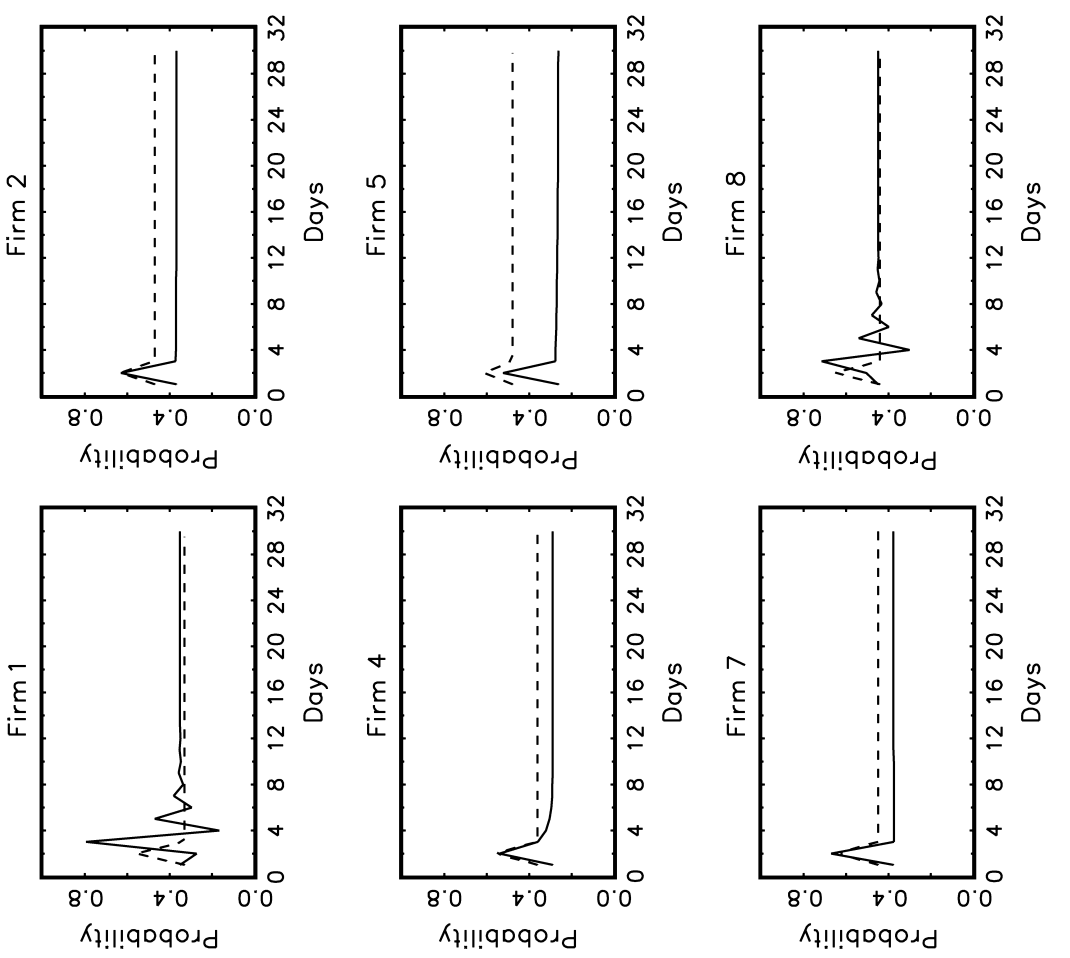

0
0
0
0
0
0
0
0
0
0
0
0
0
0
0
0
0
0
0
0
0
0
0
0
0
0
0
0
0
0
0
0
0
0
0
0
0
0
0
0
0 

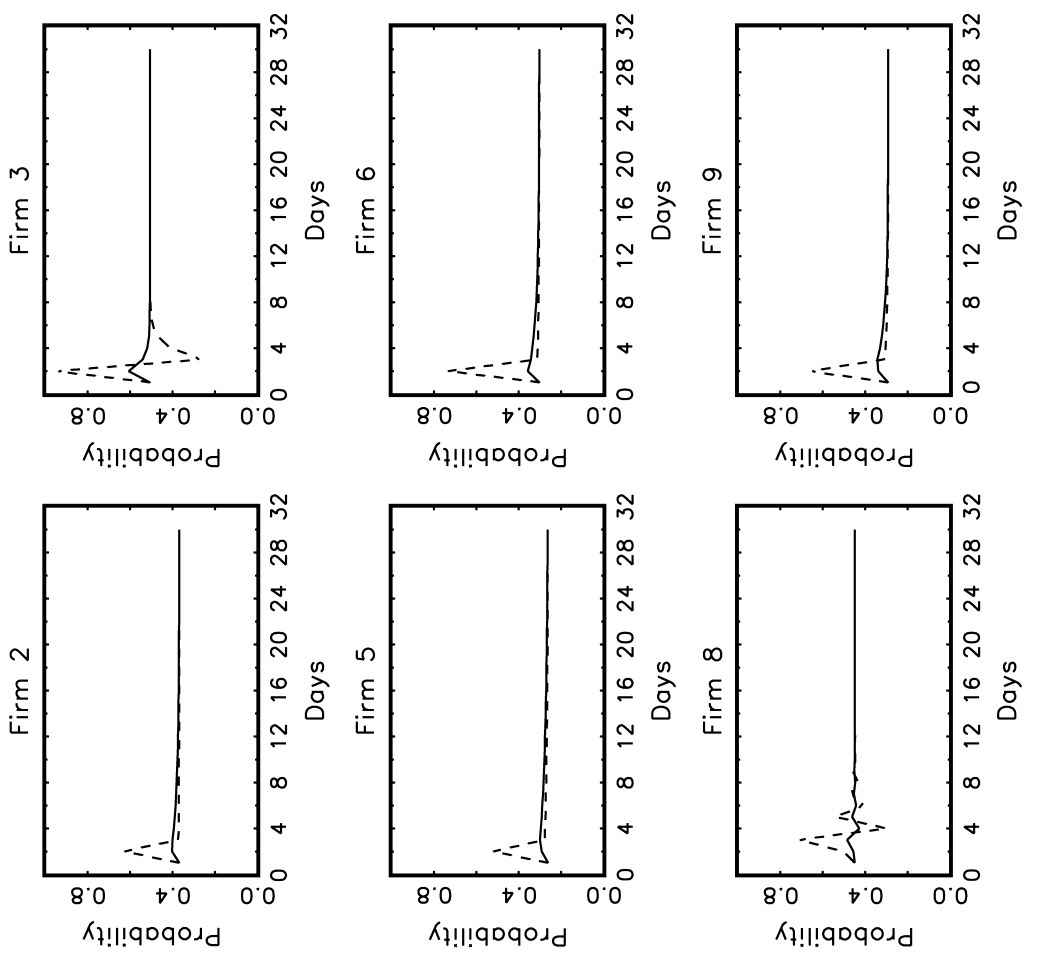

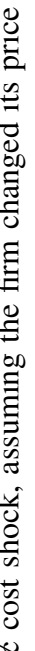
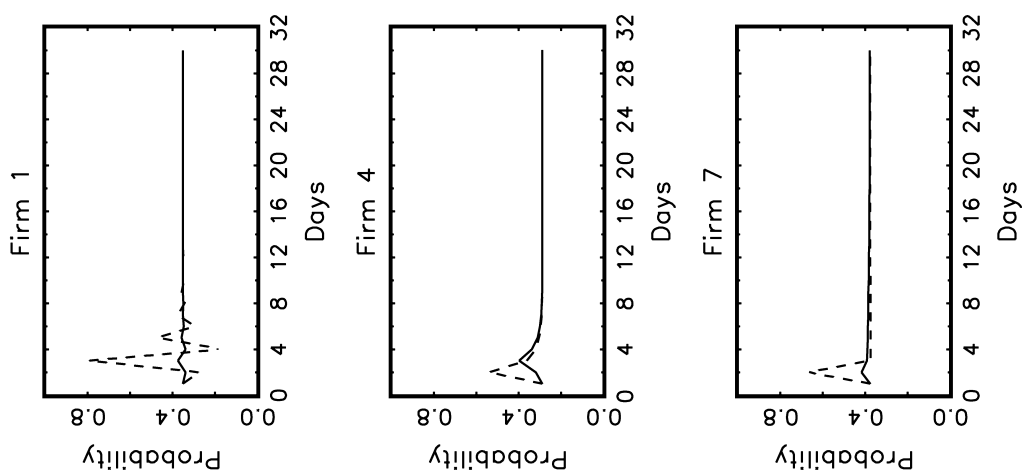

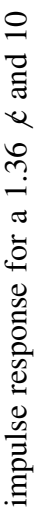

己

i

瓷 
and

$$
h_{t}=G\left[\widetilde{\omega}+\widetilde{\gamma_{1}}\left(\left|\overline{P_{t}-P_{t}^{*}}\right|+10\right)\right] \quad \text { for } \quad t \geq 1
$$

Figure 3 plots the simulated probabilities for this scenario. Here the logit predicts that the probability of a price change rises immediately following the shock and remains at the same level throughout the days when the price remains unchanged. Contrast this with the ACB. Here too, the probability of a price change rises immediately following a shock. However, for the firms with $\beta>0$, each day that passes without a price change lowers the probability of a price change the next day, until a new steady state is reached. Thus, if firms do not instantly increase their price in the face of a cost shock, it becomes less and less likely they will do so in the future.

\subsection{Asymmetry in the 'small' or in the 'large'?}

Because we find the previous day's gap, $\left|P_{t-1}-P_{t-1}^{*}\right|$, to be statistically significant in the ACB specification, we explore the asymmetry of price adjustments by adding one lag of the positive $\left(\theta_{t-1}\left(P_{t-1}-P_{t-1}^{*}\right)\right)$ and negative $\left(-\left(1-\theta_{t-1}\right)\left(P_{t-1}-P_{t-1}^{*}\right)\right)$ gaps in the set of explanatory variables in the asymmetric specification given by equation (6). Table VI presents these estimation results. Three sources of asymmetry are evident here. First, for five of the nine firms, the positive and/or negative constant is statistically significant, and the negative constant is larger than the positive constant. This suggests that firms are more likely to increase their price in response to a small negative gap than to lower it in response to a small positive one. Second, we find the coefficient on the positive current gap to be significant for six of the nine firms, with the positive gap being larger than the negative gap. Hence, firms are more likely to cut their price in response to a large positive gap than raise it in response to a large negative one. For four firms, a log-likelihood test rejects the symmetric ACB model in favor of the asymmetric model (last column, Table VI). Third, for all firms, the coefficient on $\theta_{t-1}\left(P_{t-1}-P_{t-1}^{*}\right)$ is larger than the coefficient on $-\left(1-\theta_{t-1}\right)\left(P_{t-1}-P_{t-1}^{*}\right)$, indicating a firm is more likely to cut its price today if yesterday's gap is large and positive than raise it today if yesterday's gap is large and negative.

To better illustrate the asymmetry, Figure 4 plots the probability of a price change as the difference between $P_{t}$ and $P_{t}^{*}$ varies between -10 and +10 cents per gallon for both the asymmetric logit and the ACB with current and lagged asymmetry. The dashed line is the asymmetric logit specification illustrated in Figure 1 of $\mathrm{DH}^{19}$ The solid line is the asymmetric ACB found by setting $G^{-1}\left(h_{t}\right)$ equal to its average, $x_{t}$ equal to the frequency of a price change for that firm, and the lagged gap equal to the previous day gap. Note the finding of asymmetry is robust between the two models, though firms 5, 7, and 9 have somewhat flatter response probabilities compared to the logit, suggesting a somewhat smaller degree of asymmetry. ${ }^{20}$ For firm 3 , the $\mathrm{ACB}$ implies a higher degree of asymmetry than the logit specification.

\footnotetext{
${ }^{19}$ Because the asymmetric logit and asymmetric $\mathrm{ACH}$ plots in $\mathrm{DH}$ are nearly identical, we only report the former.

${ }^{20}$ Note that we reject the null hypothesis of symmetry for firm 7 despite the asymmetric plot being somewhat flatter than in DH. Figure 3 indicates that the likely reason for this result is asymmetry in the 'small' for values of the gap close to zero.
} 

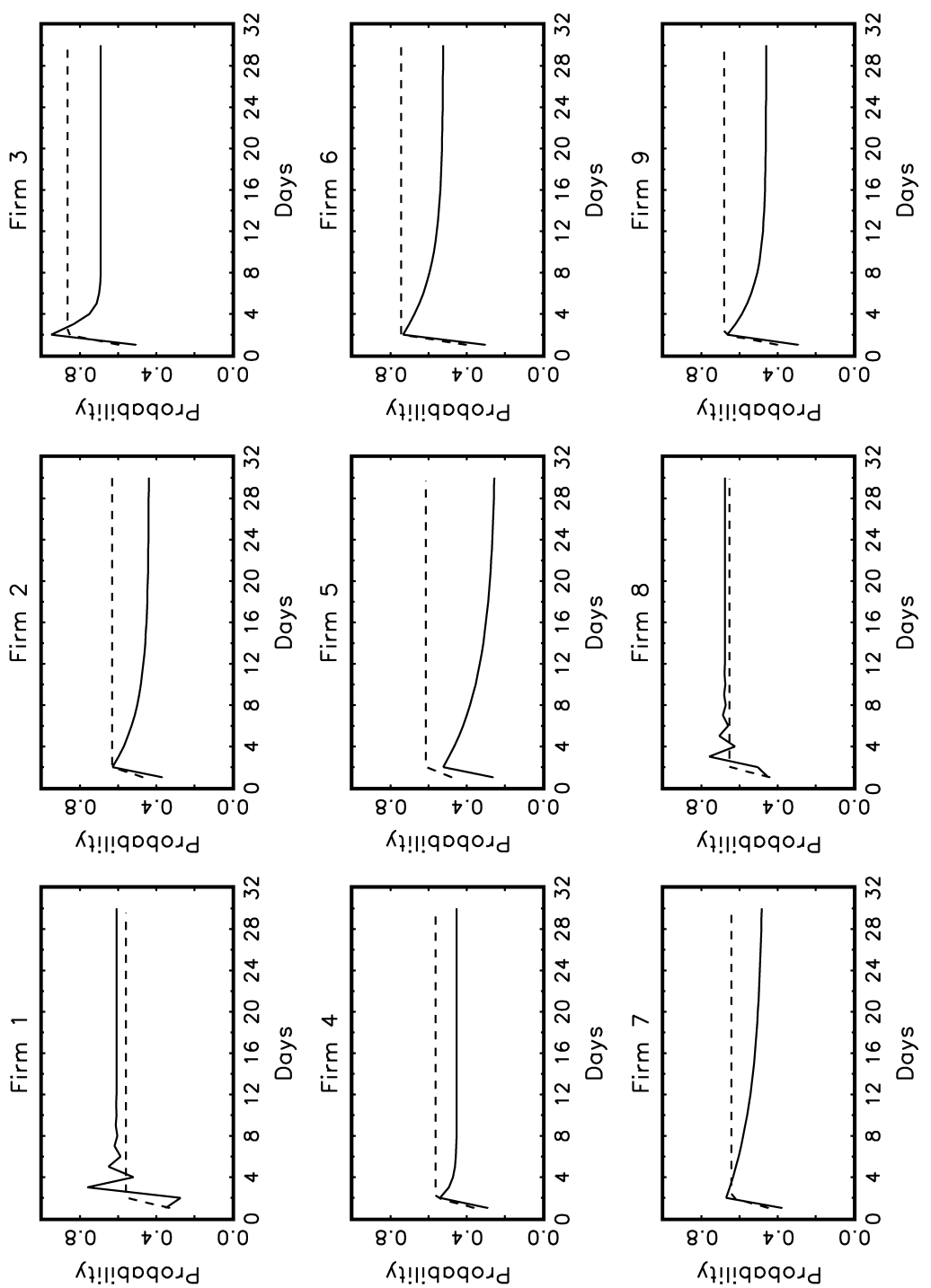

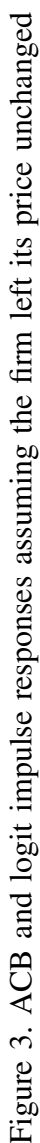




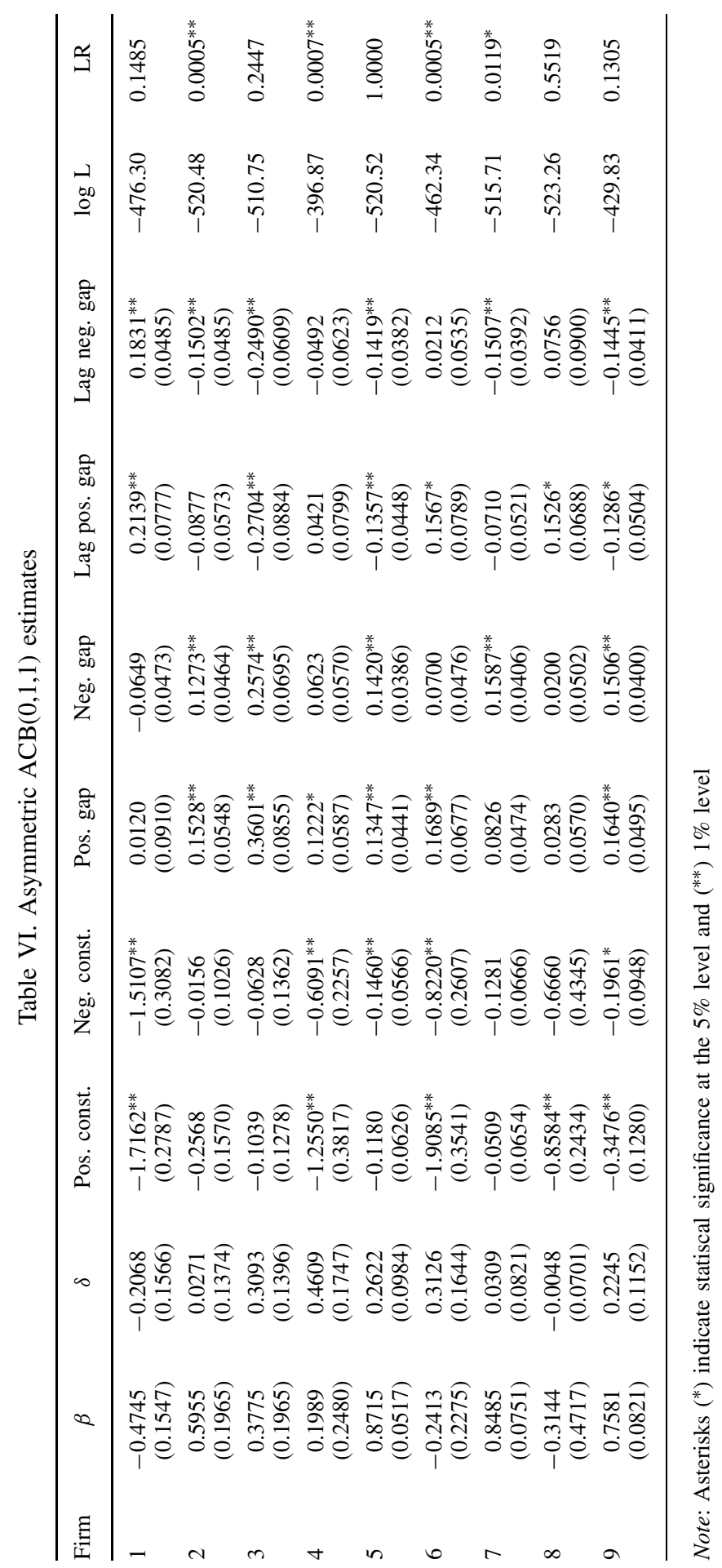



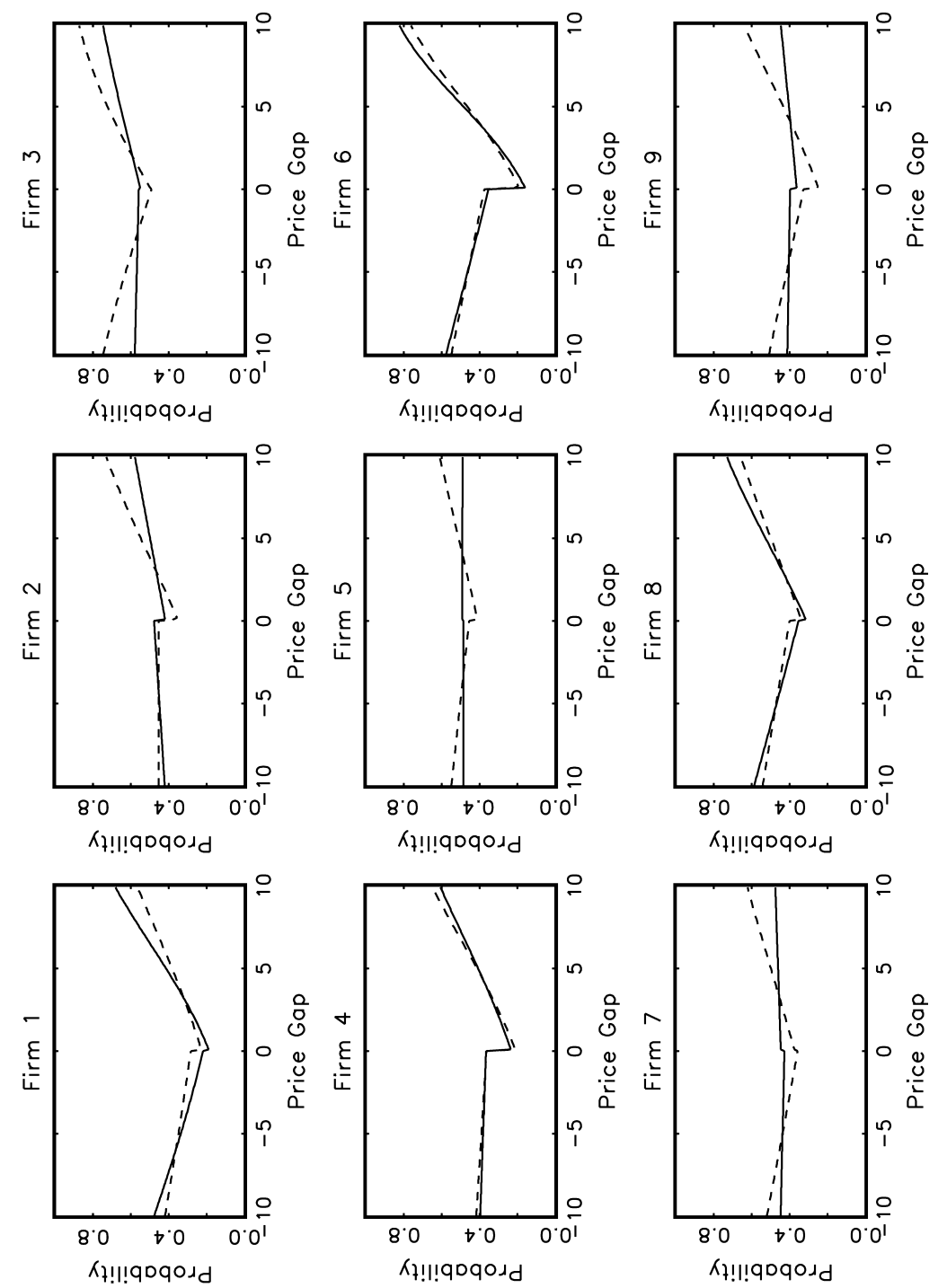

0
0
0
0
0
$\vdots$
0
0
0
0
0
0
0
0
0
0
0
0
0
0
0
0
0
0
0
0
0
0
0
0
0 


\section{DISCUSSION}

\subsection{Which theory is consistent with the data?}

Authors of theoretical models of price stickiness based on information processing delays and strategic interactions readily concede that on the surface their explanations can essentially seem like a menu cost one. For example, Rotemberg (2005) states that 'fear of customer revaluation of the firm's fairness can act as a "fixed" cost of price changes that keeps firm prices constant' (p. 840), while Reis (2006b) points out that 'the inattentiveness model instead stresses an interpretation of menu cost as fixed costs of acquiring information, and especially of absorbing and processing it' (p. 814). However, as Reis (2006b) also points out, 'this change in interpretation [menu cost vs. information-processing delays] may seem slight, but it turns out to imply a very different model and implications for inflation dynamics' (p. 814).

Thus, rejecting the pure menu cost model, but finding a menu cost being 'broadly consistent' with the data, makes it difficult to make this important distinction between competing explanations. We argue that the ACB results allow us to do so. First, $\beta>0$ suggests that the current day's probability of a price change is correlated with the previous day's, for seven of the nine firms. Second, Figure 1 suggests that in the face of a cost shock the probability of a price change instantly rises and then immediately returns to the steady state, suggesting that firms instantly pass this cost increase to their consumers. This is also illustrated by the coefficient on $\left|P_{w 1(t)}-P_{w 1(t)}^{*}\right|$ (the amount of the gap remaining after the last price change) estimated to be insignificant for all the firms. Additionally, Figure 3 indicates that if firms do not immediately increase their price in response to a cost shock, they are less likely to do so on subsequent days. Third, the asymmetric results in Table VI and Figure 4 imply asymmetry 'in the large' in the form of firms being more likely to decrease their price in response to a large positive gap than increase it in response to a large negative gap. Recall from Section 3.2 (see Table II) that these three findings are what we would expect if 'fairness' was responsible for price stickiness in this market.

Also note from Table VI and Figure 4 that we observe some 'asymmetry in the small', with firms being more likely to raise their price when the gap is small and negative than when it is small and positive. Such behavior would be consistent with rational inattention by consumers coupled with (i) a menu cost further down the supply chain (Ray et al., 2006), or (ii) profit-maximizing firms concerned with fairness. In fact, Table III suggests that wholesale price increases are, on average, less than $1 \not k$. Yet retail gasoline stations change their price in increments of $1 \not k$ or greater. This may prevent retailers from matching small wholesale price increases. Additionally, if consumers are inattentive and firms are concerned about fairness, then firms will pass on small price increases, as those will not upset consumers. Thus fairness may be working in tandem with rational consumer inattention to produce 'asymmetry in the small'.

Contrast these two explanations with the competing ones. The finding of $\beta, \delta$, and the coefficient on $\left|P_{t-1}-P_{t-1}^{*}\right|$ to be statistically significant, as well as the finding of asymmetry, runs contrary to the predictions of a menu cost model. Thus we can reject both the pure Dixit (1991) menu cost model, and the idea that the results are 'broadly consistent' with the predictions made by a typical menu cost model. The finding of $\beta$ and $\delta$ both estimated to be positive and significant for seven of the nine firms runs contrary to the ideas of information-processing delays and rational inattention by producers. Recall that information-processing delays on the part of producers suggests that the probability of a price change on successive days is very low (i.e., $\beta<0$ and $\delta<0$ ).

Another way to test for rationally inattentive producers would be to include the absolute value of the price gap at the last adjustment, $\left|P_{\text {last }}-P_{\text {last }}^{*}\right|$. The reason for this is that adjustment in 
the inattentiveness model is recursively time-contingent and a function of the state at the last adjustment. Thus a large difference between the actual and optimal price at the last adjustment date should signal to a firm that losses will rapidly occur if the firm remains inattentive for a long period of time. That is, $\left|P_{\text {last }}-P_{\text {last }}^{*}\right|$ should contain positive predictive power for a subsequent price change. The results for this additional variable are very similar to those for $\left|P_{t-1}-P_{t-1}^{*}\right|{ }^{21}$ That is, for seven out of the nine firms $\left|P_{\text {last }}-P_{\text {last }}^{*}\right|$ enters with a negative sign, contrary to what would be implied by 'sticky information' due to inattentive producers.

Additionally, rational inattention by producers predicts no asymmetry. Yet, we find asymmetry both in the small and in the large. The asymmetry suggests deliberate behavior, rather than information-processing delays, on the part of the firm. If retail stations are concerned about being treated fairly, gasoline wholesalers have an incentive to make large price decreases over large price increases. Also, if retailers cannot match small price changes or are inattentive in general, wholesalers have an incentive to make small price increases over small price decreases. Hence, rather than being inattentive themselves, wholesalers can take advantage of the inattentiveness of retailers. We should note that from Figure 4 firms 5, 7, and 9 show little evidence of asymmetry in the large. Yet these three firms show all the other characteristics that correspond to fairness $\left(\beta>0,\left|P_{w 1(t)}-P_{w 1(t)}^{*}\right|\right.$ insignificant, and cost shocks instantly passed through to consumers as demonstrated in Figure 1). Thus the absence of asymmetry does not necessarily rule out fairness for these firms.

Our results therefore suggest that the motivation for price stickiness in the wholesale gasoline market stems mainly from fairness concerns in everyday pricing, especially with regard to large price increase possibly coupled with a 'menu cost' that forces retailers to be inattentive to small price changes. Hastings and Gilbert (2005) point out that the gasoline retailer can switch its wholesaler supplier in the long run, as the retailer can buy branded gasoline from any wholesaler selling that particular brand. Moreover, contracts between the retailer and wholesaler can expire rather quickly. The Majority Staff on the US Senate Permanent Subcommittee on Investigations (2002) found that contracts can cover a period 'of one day to one year'. Clearly, switching is less likely to occur if the wholesaler is deemed to be pricing fairly by the retailer. Additionally, during supply disruptions, wholesalers often limit deliveries to retail stations, giving evidence that nonprice methods of rationing — in lieu of large price increases — are relevant (Henly et al., 1996), as fairness would predict.

A final check for whether strategic interactions among competitors play an important role in explaining price stickiness can be conducted by testing whether the past behavior of other wholesalers affects a specific wholesaler's price change probability. To test this hypothesis, we construct an average indicator of the lagged price change, $y_{t-1}^{\text {other }}$, for all the wholesalers other than the wholesaler in question. This variable ranges from 0 , when none of the other firms in the sample changed their price, to 1, when all other firms in the sample changed their price. For example, when looking at firm $1, y_{t-1}^{\text {other }}=0.5$ would indicate half of the other firms (a total of four) changed their price on the previous day. This variable appears in a positive and statistically significant manner in the ACB for all firms except for 3, 5, and 9 (see Table V). Because we only have information on nine wholesalers, and not the universe of wholesalers in Philadelphia, we take this result only as suggestive of strategic interactions among competitors.

${ }^{21}$ Results are not reported here but are available upon request. 


\subsection{Capturing Time Dependence}

Davis and Hamilton (DH, 2004) explore the role of time dynamics in the station's pricing decision by estimating the autoregressive conditional hazard $(\mathrm{ACH})$ model of Hamilton and Jordà (2002). The ACH model generalizes the autoregressive conditional duration (ACD) model of Engle and Russell (1998) by converting the ACD into a $\{0,1\}$ Bernoulli process and allowing for the expected duration to depend on exogenous covariates in a linear manner. Let $u_{n}$ denote the amount of time, or duration, between the $n$th and the $(n+1)$ th time a firm changes its price; $\psi_{n}$ denote the conditional expectation of $u_{n}$ given past durations $u_{n-1}, u_{n-2}, \ldots u_{1}$; and $N(t)$ denote the number of times that the firm has been observed to change the price as of day $t$. Following Hamilton and Jordá (2002), DH assume an exponential specification for the durations. Hence the probability of a price change on day $t+1$ is given by

$$
h_{t+1}=\frac{1}{\psi_{N(t)}+\gamma^{\prime} \mathbf{z}_{t}}
$$

where

$$
\psi_{n}=\alpha \sum_{i=1}^{n-1} \beta^{i-1} u_{n-i}+\beta^{n-1} \bar{u}
$$

and $\bar{u}$ is the average duration over the sample. The log-likelihood for the ACH is given by equation (4) and thus can be numerically maximized to obtain estimates of $\alpha$ and $\beta .^{22}$ Using both the $\mathrm{ACH}$ and the logit, or $\mathrm{ACB}(0,0,0)$, the authors find $\left|P_{t-1}-P_{t-1}^{*}\right|$ to be significant for only two firms (in contrast with the $\mathrm{ACB}$, which finds it significant for seven firms) and $\left|P_{w 1(t)}-P_{w 1(t)}\right|$ significant for none. Since the ACH outperforms the atheoretical logit in terms of goodness of fit for only one firm (firm 5), the authors find little evidence of time dependence in the price change decision. ${ }^{23}$ As a result, they conclude that 'the history of prices matters for the probability of a price change only through the current value of the price gap.' Thus they find that the menu cost model makes predictions that are 'broadly consistent' with the data.

We find considerably more evidence of serial dependence in the probability of a price change with the ACB model than found by $\mathrm{DH}$ using the ACH specification. The ACB finds time dependence in the firm's pricing decision through the past response probabilities $(\beta$ significant for all firms) and to a lesser extent, through the lagged indicator of a price change ( $\delta$ significant for four out of nine firms). Why do DH find only limited evidence of time dependence?

We begin to investigate the role of durations by estimating an $\operatorname{ACB}(0,1,1)-\operatorname{ACD}(1,1)$ model where the logarithm of the current duration, as well as the current and previous day's gaps, are included in the ACB. The ACD is assumed to take the Nelson form, given by equation (5). We then test the null hypothesis that the coefficient on the logarithm of the contemporaneous duration in the ACB is equal to zero. The $p$-value for this hypothesis test is reported on the second column of Table VII. We find evidence that contemporaneous durations have additional explanatory power only for two firms (1 and 3). The estimates for the remaining explanatory variables are virtually identical to those of the $\operatorname{ACB}(0,1,1)$ reported in Table IV. ${ }^{24}$

\footnotetext{
${ }^{22}$ In order to ensure the estimated probability falls between 0 and 1, the denominator of equation (13) is replaced with a differentiable smoothing function as detailed in Hamilton and Jordà (2002).

${ }^{23}$ We refer the reader to Table III of Davis and Hamilton (2004).

${ }^{24}$ Results are available upon request. Estimation results are also robust to Engle and Russell (2005) event-time specification where we lag $\left(x_{t-1}-h_{t-1}\right)$ rather than $x_{t-1}$.
} 
Table VII. Tests for significance of the duration

\begin{tabular}{llll}
\hline Firm & $\ln \left(u_{N(t)}\right)$ & $\ln \left(u_{N(t)-1}\right)$ & $u_{N(t-1)-1}$ \\
\hline 1 & $0.0080^{* *}$ & 0.644 & 0.0513 \\
2 & 0.7323 & 0.0557 & 1.000 \\
3 & $0.0161^{*}$ & 0.1797 & 0.1573 \\
4 & 0.2404 & 0.1923 & 0.9542 \\
5 & 0.1948 & 0.1897 & $0.00130^{* * *}$ \\
6 & 0.2744 & 0.1512 & 0.2184 \\
7 & 0.4074 & 0.5271 & 0.8559 \\
8 & 0.2806 & 0.8415 & 1.000 \\
9 & 0.7675 & 0.4976 & 0.1505 \\
\hline
\end{tabular}

Note: Column 2 reports the $p$-value for the test of the null hypothesis that the natural log of the contemporaneous duration in the ACB-ACD model is zero. Column 3 reports the $p$-value for the test of the null hypothesis that the lagged duration is equal to zero in the logit model with the current price gap. Asterisks indicate significance at the * $5 \%$ level and ${ }^{* *} 1 \%$ level.

One may argue that these results are driven by the fact that we include the logarithm of the contemporaneous duration and not the lagged duration as explanatory variable in the ACB specification. Recall from equation (14) that the ACH uses the lagged level of the duration, not the log-duration to predict price changes. To explore this possibility, we first replicate the $\operatorname{ACB}(0,1,1)-\mathrm{ACD}(1,1)$ estimation adding the logarithm of the lag duration, $\ln \left(u_{N(t-1)-1}\right)$, in the ACB. The first column of Table VII reports the $p$-value for the test of the null hypothesis that the coefficient on $\ln \left(u_{N(t-1)-1}\right)$ is equal to zero. We cannot reject the null for any of the firms. We then estimate the logit- $\mathrm{ACB}(0,0,0)$ - model with $\left|P_{t}-P_{t}^{*}\right|$ and the lagged level of the duration as explanatory variables, and test the null hypothesis that the lagged level of the duration is equal to zero. The fourth column of Table VII reports the $p$-values for this test. For all firms except firm 5, the lagged duration is not significant in the logit model. Thus it is not surprising that the $\mathrm{ACH}$ outperforms the logit only for this one firm in DH.

As a final comparison between the ACH and ACB we use Rivers and Vuong's (2002) model selection test for non-nested models, which extends Vuong's (1989) likelihood ratio statistic to dynamic models. The null hypothesis is

$$
H_{0}: E_{0}\left[\widehat{l}_{t}^{\mathrm{ACH}}-\widehat{l}_{t}^{\mathrm{ACB}}\right]=0
$$

which states that the two models are equally close to the true specification. The test statistic follows a standard normal distribution. Hence the ACB specification is preferred at a 5\% significance level if the test statistic is greater than 1.65. The last column of Table IV reports the test results. For eight of the nine firms we reject the null hypothesis in favor of the ACB at the $10 \%$ level.

Summarizing, our $\operatorname{ACB}(0,1,1)-\operatorname{ACD}(1,1)$ estimation results suggest that dynamics play an important role in the probability of price changes. However, this time dependence does not stem from the role of durations (as posited by the $\mathrm{ACH}$ ), but directly from the past distribution of the price changes and, less often, from the indicator of a price change.

\section{CONCLUSIONS}

Why are wholesale gasoline prices sticky? In this paper, we consider three categories of price stickiness: (a) menu costs; (b) information processing due to sticky information, 'inattentive' 
producers or consumers; and (c) strategic interactions in the form of partial adjustment and fair pricing. To evaluate these hypotheses we estimate an autoregressive conditional binomial (ACB) model where the probability that a firm will change its price on day $t$ is modeled as a function of the historic distribution of price changes, past price change realizations, and the current and lagged gap between the wholesale price and the optimal price. While we do find some heterogeneity amongst firms, two important similarities stand out: the strong time dependence and the asymmetric response.

Whereas the finding of asymmetry is not new, in contrast with DH (2004), we find significant evidence of time dependence in the probability of price changes. Specifically, our results indicate that the history of prices matters for the probability through the historic distribution, the value of the previous day's price gap, and the lagged indicator of a price change. Furthermore, by estimating the probability of a price change and the duration process jointly in the ACB-ACD model, we show that the duration between price changes is only significant for two of the nine firms. Because the lag of the duration is the foundation of the ACH model (see equations (13) and (14)), these results suggest that time dynamics in wholesale gasoline prices are better captured through the past distribution of price changes (ACB) than through past durations $(\mathrm{ACH})$.

Our results have implications regarding which theory best fits the observed wholesale gasoline data. First, the empirical evidence is not consistent with the menu cost explanation. As we mentioned before, pure menu cost models such as Dixit's posit that the history of price changes should only be significant through the current price gap and predicts a symmetrical response to a cost change. Neither is the case here. The finding of positive autocorrelation in the firm's price change decision $(\beta>0$, and $\delta>0)$, as well as the finding of asymmetry, offers evidence against information-processing delays on behalf of the firm. However, the strong autocorrelation of price change probabilities, the immediate pass-through of cost shocks (Figure 1), and finding that firms are more likely to make large price decreases over large price increases (Table VI and Figure 4) are consistent with the idea of 'fair pricing' (Kahneman et al., 1986). That is, it is likely that prices in this market go unchanged if the wholesaler's customers (i.e., retail gasoline stations) believe such a change would be unfair. Given that the relationship between wholesaler and retailer is long term, fairness is likely to be a practical concern. Thus, like Davis and Hamilton (2004), we conclude that strategic considerations are important. Yet we are able to narrow this motivation down to one of 'fairness'. Additionally, we find some evidence of asymmetry 'in the small' (i.e., small price increases are more likely than small price decreases) that could be consistent with rational inattention by consumers coupled with (a) retailers being precluded from matching small wholesale price changes (Ray et al., 2006), or (b) profit-maximizing firms who are concerned about fairness.

\section{ACKNOWLEDGEMENTS}

This paper was completed while Ana María Herrera was visiting Harvard's Kennedy School of Government under a Repsol-YPF research fellowship. This paper has benefited from discussions with numerous people, including seminar participants at Repsol-YPF Harvard Kennedy School Workshop, Emory University, the Federal Reserve Bank of Atlanta, and the 2006 Society for Nonlinear Dynamics and Econometrics Meetings. We especially thank Anthony Creane, Bill Hogan, Lutz Kilian, Jeffrey Wooldridge, two anonymous referees and the editor for helpful comments, and Michael Davis and Jim Hamilton for sharing their data. 


\section{REFERENCES}

Aguirregabiria V. 1999. The dynamics of markups and inventories in retailing firms. Review of Economic Studies 66: 275-308.

Barro R. 1972. A theory of monopolistic price adjustment. Review of Economic Studies 39: 17-26.

Bils M, Klenow P. 2004. Some evidence on the importance of sticky prices. Journal of Political Economy 112: 947-985.

Borenstein S, Cameron C, Gilbert R. 1997. Do gasoline prices respond asymmetrically to crude oil price changes? Quarterly Journal of Economics 112: 305-339.

Calvo J. 1983. Staggered Prices in a Utility-Maximizing Framework. Journal of Monetary Economics 12: 383-398.

Chari V, Kehoe P, McGrattan E. 2000. Sticky price models of the business cycle: can the contract multiplier solve the persistence problem? Econometrica 68: 1151-1180.

Clarida R, Gali J, Gertler M. 1999. The science of monetary policy: a new Keynesian perspective. Journal of Economic Literature 37: 1661-1707.

Davis M. 2007. The dynamics of daily retail gasoline prices. Managerial and Decision Economics 28: 713-722.

Davis M, Hamilton J. 2004. Why are prices sticky? The dynamics of wholesale gasoline prices. Journal of Money, Credit, and Banking 36: 17-37.

Dixit A. 1991. Analytical approximations in models of hysteresis. Review of Economic Studies 58: $141-151$.

Dotsey M, King R. 2006. Pricing, production, and persistence. Journal of the European Economic Association 4: 893-928.

Engle R, Russell J. 1998. Autoregressive conditional duration: a new model for irregularly spaced transaction data. Econometrica 66: 1127-1162.

Erceg C, Henderson D, Levin T. 2003. Optimal monetary policy with staggered wage and price contracts. Journal of Monetary Economics 46: 281-313.

Fishman A, Simhon A. 2005. Can small menu costs explain sticky prices? Economic Letters 87: $227-230$.

Hamilton J, Jordà O. 2002. A model for the federal funds rate target. Journal of Political Economy 110: $1135-1167$.

Hastings J. 2004. Vertical relationships and competition in retail gasoline markets: empirical evidence from contract changes in Southern California. American Economic Review 94: 317-328.

Hastings J, Gilbert R. 2005. Market power, vertical integration, and the wholesale price of gasoline. Journal of Industrial Economics 53: 469-492.

Henly J, Potter S, Town R, 1996. Price Rigidity, the Firm, and the Market: Evidence from the wholesale Gasoline Industry During the Iragi Invasion of Kuwait. Unpublished Working paper.

Kahneman D, Knetsch J, Thaler R. 1986. Fairness as a constraint on profit seeking: entitlements in the market. American Economic Review 76: 728-741.

Levy D. 2007. Price rigidity and flexibility: new empirical evidence. Managerial and Decision Economics 28: 639-647.

Levy D, Bergen M, Dutta S, Venable R. 1997. The magnitude of menu costs: direct evidence From large U.S. supermarket chains. Quarterly Journal of Economics 112: 791-825.

Lewis M. 2003. Asymmetric Price Adjustment and Consumer Search: An Examination of the Retail Gasoline Market. Discussion Paper 0407010 Center for the Study of Frenzy Markets.

Majority Staff on the Permanent Senate Subcommittee on Investigations. 2002. Gas Prices, How Are They Really Set? Report.

Mankiw NG. 1985. Small menu costs and large business cycles: a macroeconomic model of monopoly. Quarterly Journal of Economics 100: 529-537.

Mankiw NG, Reis R. 2002. Sticky information versus sticky prices: a proposal to replace the new Keynesian Phillips curve. Quarterly Journal of Economics 117: 1295-1328.

Nelson D. 1991. Conditional heteroskedasticity in asset returns: a new approach. Econometrica 59: 347-370.

Noel M. 2007a. Edgeworth price cycles: evidence from the Toronto retail gasoline market. Journal of Industrial Economics 55: 69-92.

Noel M. 2007b. Edgeworth price cycles, cost based pricing, and sticky pricing in retail gasoline markets. Review of Economics and Statistics 89: 324-334.

Okun A. 1981. Prices and Quantities: A Macroeconomic Analysis. Brookings Institution: Washington, DC. 
Ray S, Chen A, Bergen M, Levy D. 2006. Asymmetric wholesale pricing: theory and evidence. Marketing Science 25: 131-154.

Reis R. 2006a. Inattentive consumers. Journal of Monetary Economics 53: 1761-1800.

Reis R. 2006b. Inattentive producers. Review of Economic Studies 73: 793-821.

Rivers D, Vuong Q. 2002. Model selection tests for nonlinear dynamic models. Econometrics Journal 5: $1-39$.

Rotemberg J. 1982. Monopolistic price adjustment and aggregate output. Review of Economic Studies 49: $517-531$.

Rotemberg J. 2005. Customer anger at price increases, time variation in the frequency of price changes and monetary policy. Journal of Monetary Economics 52: 829-852.

Rotemberg J. 2006. Fair Pricing. NBER Working Paper No 10915.

Rotemberg J, Woodford M. 1997. An optimization-based econometric framework for the evaluation of monetary policy. In NBER Macroeconomics Annual, Bernanke B, Rotemberg J (eds). MIT: Cambridge, MA; 297-361.

Russell J, Engle R. 2005. A discrete-state continuous-time model of financial transactions prices and times: the autoregressive conditional multinomial-autoregressive conditional duration model. Journal of Business and Economic Statistics 23: 166-180.

Schwarz G. 1978. Estimating the dimension of a model. Annals of Statistics 6: 461-464.

Sheshinski E, Weiss Y. 1977. Inflation and the costs of price adjustment. Review of Economic Studies 44: 287-303.

Sheshinski E, Weiss Y. 1983. Optimum pricing policy under stochastic inflation. Review of Economic Studies 50: $513-529$.

Sims C. 1998. Stickiness. Carnegie-Rochester Conference Series on Public Policy 49: 317-356.

Sims C. 2003. Implications for rational inattention. Journal of Monetary Economics 50: 665-690.

Slade M. 1998. Optimal pricing with costly adjustment: evidence from retail-grocery prices. Review of Economic Studies 65: 87-107.

Slade M. 1999. Sticky prices in a dynamic oligopoly: an investigation of $(\mathrm{s}, \mathrm{S})$ thresholds. International Journal of Industrial Organization 17: 477-511.

Tappata M. 2008. Rochets and Feathers. Understanding Asymmetric Pricing. Forthcoming, RAND Journal of Economics.

Trench C. 2001. How Pipelines Make the Oil Market Work: Their Networks, Operation, and Regulation. Memorandum prepared for the Association of Oil Pipe Lines and the American Petroleum Institute's Pipeline Committee.

Vuong Q. 1989. Likelihood ratio tests for model selection and non-nested hypotheses. Econometrica 57: $307-333$. 